\title{
How are health literacy principles incorporated into breast cancer chemotherapy education? A review of the literature
}

\author{
Pearman D. Parker*1, Sue P. Heiney ${ }^{1}$, Daniela B. Friedman ${ }^{2,3}$, Tisha M. Felder ${ }^{1,3}$, Robin Dawson Estrada ${ }^{1}$, Eboni \\ Herbert Harris ${ }^{1}$, Swann Arp Adams ${ }^{1,3,4}$ \\ ${ }^{1}$ College of Nursing, University of South Carolina, Columbia, South Carolina, United States \\ ${ }^{2}$ Department of Health Promotion, Education, and Behavior, Arnold School of Public Health, Columbia, South Carolina, United \\ States \\ ${ }^{3}$ Statewide Cancer Prevention and Control Program \\ ${ }^{4}$ Department of Epidemiology \& Biostatistics, Arnold School of Public Health, Columbia, South Carolina, United States
}

Received: November 5, 2017

DOI: $10.5430 /$ jnep.v8n6p77
Accepted: December 28, $2017 \quad$ Online Published: January 16, 2018

URL: https://doi.org/10.5430/jnep.v8n6p77

\begin{abstract}
Background: Chemotherapy is commonly used in combination with other treatments for breast cancer. However, low adherence to chemotherapy is a growing concern, particularly among breast cancer patients. Side effects such as nausea and vomiting, fatigue, and arthralgia can contribute to reduced adherence. Other factors such as provider communication and limited insurance coverage can affect adherence. Studies have shown that as much as $28 \%$ of patients with breast cancer did not continue with their prescribed dose of chemotherapy. Research suggests that chemotherapy education materials can be critical to addressing problems with non-adherence, and may include written materials, verbal instruction, and multimedia programs. Despite this wide variety, the effectiveness and benefit of chemotherapy education hinges on the patients' health literacy. Breast cancer patients with low health literacy may be unclear about chemotherapy or face difficulty adhering to treatment if they do not understand the information provided to them. Thus, this scoping review summarizes the existing research on how health literacy principles are incorporated into breast cancer chemotherapy education materials.

Methods: Using a combination of keywords (e.g. chemotherapy, education) and Medical subject headings (MeSH) terms (e.g., drug therapy, antineoplastic agents), we searched five databases (1977-2017): CINAHL, PubMed, PsycINFO, Cochrane Library, and Web of Science.

Results: Eight of 4,624 articles met the inclusion criteria. Five articles incorporated health literacy principles (e.g., plain language, maintaining an active voice, using white space) into the development of written materials. Few articles used a theoretical framework to guide education material development $(n=3)$. Of the three articles that described pilot-testing of educational materials, two used post-tests only and one used a pre/post-test design.

Conclusions: Findings indicated that limited research exists regarding the use of health literacy principles in chemotherapy education materials. Much of the development of chemotherapy education is not grounded in theory and the application of health literacy principles is limited. Implementing health literacy principles may improve overall comprehension of education thereby increasing adherence.
\end{abstract}

Key Words: Health literacy, Chemotherapy education, Breast cancer, Review paper

\footnotetext{
*Correspondence: Pearman D. Parker; Email: parkerpd@email.sc.edu; Address: College of Nursing, University of South Carolina, Columbia, SC, United States.
} 


\section{INTRODUCTION}

Each year, more than 252,710 new cases of invasive breast cancer and an additional 63,410 cases of in situ breast cancer are diagnosed. ${ }^{[1]}$ While the risk of breast cancer in men is 100 times less likely than in women, approximately 2,500 men will also receive the diagnosis. ${ }^{[1,2]}$ Currently, more than 3.1 million people have a history of invasive breast cancer. ${ }^{[1]}$ The American Cancer Society (ACS) estimates that 40,610 women and 500 men die from the disease annually. ${ }^{[1]}$

Breast cancer treatment is a significant phase along the cancer care continuum. ${ }^{[3]}$ Chemotherapy is one of the most common treatment options and adherence to chemotherapy treatment is crucial to extending survival (adherence is an agreement on the type, dosing, and frequency of a medication upon between a patient and provider). ${ }^{[4,5]}$ However, chemotherapy adherence rates are surprisingly low. For example, Hersh$\operatorname{man}^{[6]}$ found that $28 \%$ of patients with breast cancer did not receive the expected amount of intravenous chemotherapy. Surprisingly, $31 \%$ of African American women reeived fewer cycles than expected compared to $23 \%$ of White women. ${ }^{[6]}$ With regard to oral chemotherapy, the rate of adherence is a staggering $16 \% .^{[7]}$ Reasons for non-adherence include chemotherapy side effects such as nausea and vomiting, arthralgia, and fatigue. ${ }^{[8,9]}$ Other factors such as patient medication belies, provider communication, and limited insurance can also reduce adherence. ${ }^{[7]}$ As the treatment landscape continues to shift from intravenous chemotherapy toward immunotherapy, targeted therapy, and oral chemotherapy, ${ }^{[10]}$ effective chemotherapy education is critical to promote adherence and to ensure a greater quality of life for patients with breast cancer. ${ }^{[11,12]}$ Better understanding of how patients comprehend current chemotherapy educational materials is critical to developing and refining more effective strategies.

Nurses are uniquely qualified to evaluate chemotherapy educational materials, as they are on the forefront of educating patients about chemotherapy, administering medications, and guiding patients through treatment. ${ }^{[13]}$ The goals of chemotherapy education are to teach patients how to manage side effects, practice self-care to decrease symptom distress, and improve the patients' quality of life throughout the process. ${ }^{[8,13,14]}$ Nurses may use a variety of functional modalities for chemotherapy education including printed materials, verbal instruction, and multimedia programs on tablets or computers. ${ }^{[15-17]}$ Additionally, with the emergence of new cancer therapies, nurses may consider developing new or modifying existing chemotherapy educational tools.

Even if the content is appropriate, nurses may consider each patient's specific learning style to promote comprehension. ${ }^{[18]}$ Learning styles (visual, auditory, tactile, kinesthetic) affect how patients receive and process information. ${ }^{[19]}$ However, the patients' reception, retention, and comprehension of information are ultimately influenced by their level of health literacy. ${ }^{[18,20]}$ The Institute of Medicine ${ }^{[21]}$ defines health literacy as "the capacity to obtain, process, and understand basic health information and services to make appropriate health decisions" (p. 20). Individuals' health literacy can hinder or promote their comprehension and knowledge of cancer-related information. ${ }^{[22,23]}$ However, patients with low health literacy may be unclear about the treatment regimen or chemotherapy cycles. ${ }^{[24]}$ Inadequate or erroneous knowledge about adverse effects of chemotherapy results in greater hospital admissions, increased morbidity, and decreased quality of life. ${ }^{[25,26]}$

Nurses can tailor their teaching methods to adjust for their patients' health literacy level when educating about chemotherapy, including the incorporation of health literacy principles within educational materials and programs to assist the patients' comprehension. ${ }^{[27,28]}$ Health literacy principles include using plain language, active voice, friendly tone, simple definitions, graphics, and writing at fifth to sixth grade reading levels. ${ }^{[28,29]}$ Materials utilizing plain language are designed to be quickly and easily understood by the readers. ${ }^{[30]}$ Written material with plain language allows readers to locate what they need, understand what they read, and use what they find to meet their needs. ${ }^{[31]}$ Elements of plain language include writing in active voice, avoiding medical jargon, simplifying grammar, and breaking information into smaller segments. ${ }^{[30,31]}$ Moreover, the use of all capital letters, italics, and acronyms should be avoided ${ }^{[32]}$ but bulleted lists, tables, conversational tone, and implementation of basic headings are helpful. ${ }^{[29]}$

The use of visuals and graphics is related to readability and can assist the patient in understanding materials. ${ }^{[33,34]} \mathrm{Im}$ portant characteristics for written materials include: placing images in the appropriate context of the document, allowing for only one message per visual, and employing use of whitespace. ${ }^{[33,35]}$ Captions can be brief and the visuals should be concrete. ${ }^{[33,36]}$ Illustrations and graphics are recommended to be clear, show what the words describe, and have captions to help direct the patient's eyes. ${ }^{[36]}$ Using visuals according to plain language guidelines can assist the patient in understanding important information about chemotherapy. ${ }^{[30,34]}$ However, little is known as to how nurses use such health literacy principles when educating about chemotherapy. Thus, the purpose of this scoping review is to identify and examine the degree or frequency to which health literacy principles are incorporated within chemotherapy education for patients with breast cancer to serve as a guide for developing or editing materials. 


\section{MethodS}

This scoping review was used to assess the breadth of the available research literature and to examine the extent and range of studies within chemotherapy education. ${ }^{[37,38]} \mathrm{We}$ used a scoping review framework informed by Arksey and $\mathrm{O}^{\prime}$ Malley ${ }^{[38]}$ to guide our approach. Following Arksey and O'Malley, ${ }^{[38]}$ we embarked on the review and determined the research question (stage 1), identified relevant studies (stage 2 ), selected studies (stage 3), charted the data (stage 4), and collated, summarized, and reported the results (stage 5).

\subsection{Identifying relevant studies}

The authors utilized five databases: CINAHL (Cumulative Index to Nursing and Allied Health Literature), PubMed, PsycINFO, Cochrane Library, and Web of Science. Keywords were chemotherapy, education, literacy, and low literacy. Medical subject headings (MeSH) included drug therapy, antineoplastic agents, patient education handouts (publication type), patient education as topic, health literacy, and information literacy. The search strategy using MeSH terms included ("Drug Therapy" [Mesh] OR "Antineoplastic Agents" [Mesh]) OR ("Patient Education as Topic"[Mesh] OR "Patient Education Handout"[Publication Type])) AND ("Information Literacy”[Mesh] OR “Health Literacy”[Mesh]).

\subsection{Inclusion and exclusion criteria}

To be included in the analysis, articles had to be published between 1997 and 2017. Additional inclusion criteria included having: 1) descriptions of health literacy principles; 2) content on intravenous or oral chemotherapy education; 3) focus on education for patients with breast cancer; and 4) applicable to adult populations. The publications were limited to academic journals, dissertations, and conference proceeding papers in English. Articles pertaining to pediatric populations were excluded. Review articles, quality improvement studies, and editorials were also not included. See Figure 1 for detailed description of the inclusion and exclusion criteria.

Two reviewers (PP, EH) collaborated to select the final articles. The reviewers independently selected the articles based on the inclusion and exclusion criteria. Both reviewers agreed upon the final articles and had no discrepancies in their results.

\section{Results}

\subsection{Study selection}

The literature search yielded 4,624 results. After assessing for duplicates and reading through the titles and abstracts, 39 potential publications were identified as meeting the inclusion criteria for full-text review. More than 3,500 results were excluded because the title or abstract were not pertinent to breast cancer chemotherapy education. Of the 39 articles, 31 articles were excluded due to no description of health literacy principles $(n=11)$; not specific to any cancer $(n=7)$; specific to cancers other than breast cancer $(n=6)$; recommendations only for teaching $(n=2)$; quality improvement studies in education $(n=2)$; education about cancer risk ( $n$ $=2)$; and education about surgical treatment decisions ( $\mathrm{n}=$ 1). Eight articles were selected which met the objective of examining health literacy principles in chemotherapy education for patients with breast cancer. See Figure 1 for the study selection process.

\subsection{Overall findings}

Based on Arksey and O'Malley's ${ }^{[38]}$ framework, we thematically charted the data into three categories: 1) education guided by theoretical framework, 2) application of specific health literacy principles, and 3 ) use of pilot testing materials for chemotherapy education.

\subsubsection{Theoretical underpinnings}

Three articles used theoretical frameworks to guide educational material development. ${ }^{[27,39,40]}$ Rigdon $^{[39]}$ used Orem's general theory of self-care deficit. ${ }^{[41]}$ This framework guided the evaluation and development of chemotherapy content and highlighted the importance of chemotherapy knowledge to increase self-care for older adults. The theory emphasizes the role of knowledge of potential health problems in promoting self-care behaviors ${ }^{[41]}$ for older adults undergoing chemotherapy. ${ }^{[39]}$

Two studies employed the use of two variations of adult learning theories in developing chemotherapy education interventions. ${ }^{[27,40]}$ Sullivan and colleagues ${ }^{[40]}$ developed a single source of online materials to educate patients about oral chemotherapy. Adult learning principles described by Best $^{[42]}$ were implemented when designing the material. Adult learning standards included creating printed materials with larger print, maintaining black lettering on white backgrounds, and using warm colors such as red or orange to enhance visuals. ${ }^{[42-44]}$ Though the authors did not measure the participants' literacy prior to the study, they used the adult learning standards to meet diverse learning needs of adult patients. ${ }^{[40]}$ Similarly, the authors in neither of these two studies measured literacy levels prior to chemotherapy education.

Mann ${ }^{[27]}$ used two theories in a quality improvement project - adult learning theory and King's ${ }^{[45,46]}$ framework on adult learning and goal attainment - to address three domains of learning (affective, cognitive, and psychomotor) in the study. King's ${ }^{[45,46]}$ theoretical framework suggests the nurse and 
patient have a trusting relationship and mutually determine goals for the patient. Verbal and nonverbal communication are critical factors within the nurse-patient relationship. Mann ${ }^{[27]}$ focused on the nurse-patient communication aspect of chemotherapy education in her quality improvement intervention. Additionally, Mann ${ }^{[27]}$ used the OutcomesFocused Knowledge Translation Intervention Framework (OFKTIF). ${ }^{[47]}$ The OFKTIF was ideal because the framework provided guidance for improving the initial education programs. ${ }^{[27]}$ The four areas of the OFKTIF included facilitation, content, patient preference, and sources of evidence. ${ }^{[4]}$

Three articles included the use of theoretical frameworks to improve or to develop chemotherapy educational programs. Though the focus of these articles varied, each of these studies used sound theoretical approaches to guide their research. However, five of the articles were not grounded in theory or theoretical frameworks. ${ }^{[20,48-51]}$

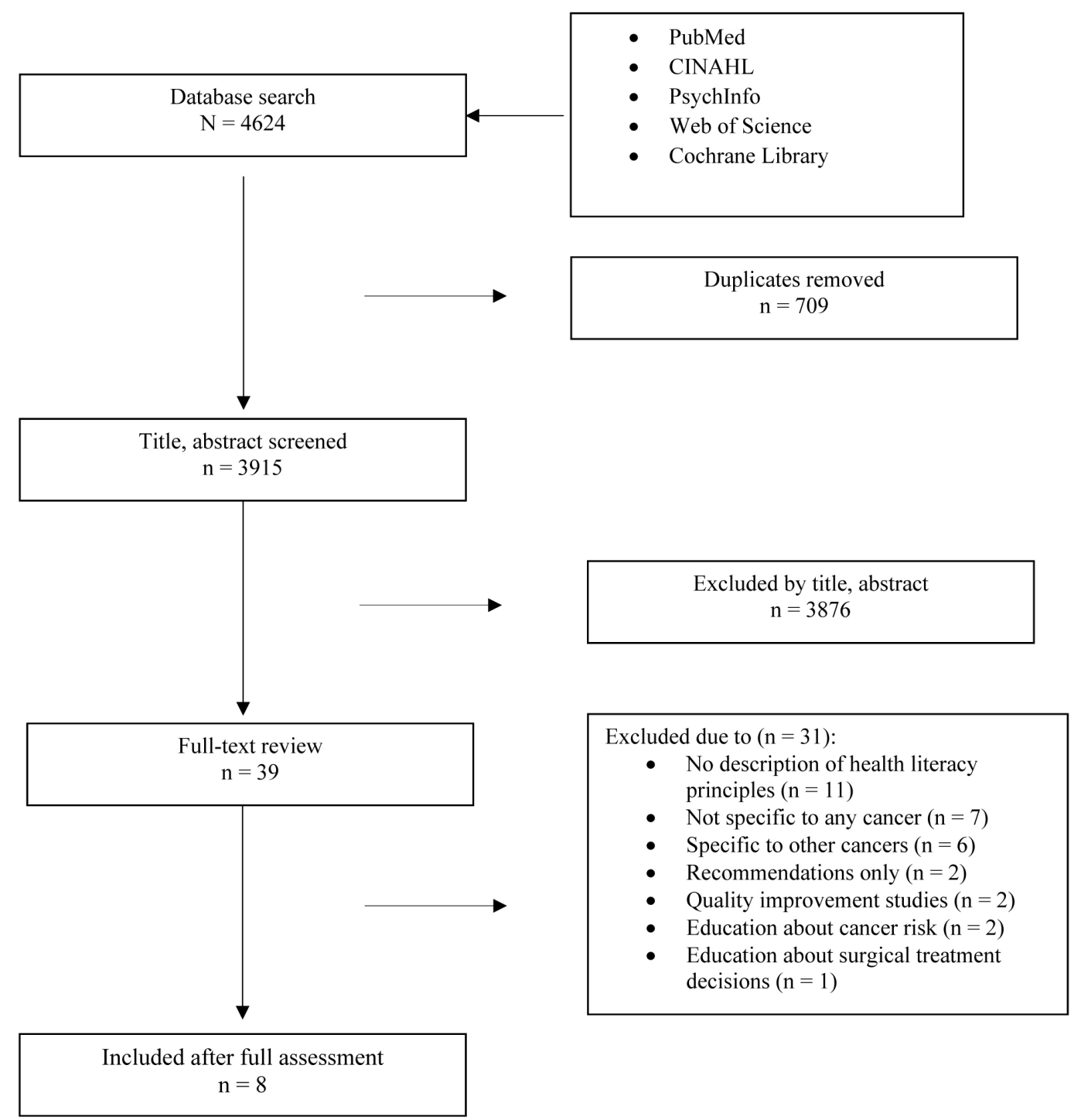

Figure 1. PRISMA (Preferred reporting items for systematic reviews and meta-analyses) Flow chart for study selection

\subsubsection{Health literacy principles}

Five articles included health literacy principles pertinent to written materials. ${ }^{[39,40,48,49,51]}$ Four articles specifically mentioned reading level and using active voice in written materials, ${ }^{[39,40,49,51]}$ whereas authors of three studies discussed the use of graphics to assist in reading comprehension. ${ }^{[39,48,51]}$
The authors of four articles mentioned specific health literacy principles to improve and develop their written educational materials. Jazieh and Brown ${ }^{[51]}$ developed a patient information packet for veterans receiving chemotherapy. The information was written at a sixth-grade reading level, and the font was increased to meet the needs of older patients. 
Participants rated the patient information packet 3.9 out of 4 on a scale of 1 to 4 from very dissatisfied to very satisfied. ${ }^{[51]}$ Participants were "very satisfied" with the large font, readability, and content. Sullivan and others ${ }^{[40]}$ also incorporated a lower reading level for their educational audiovisual resource. The authors wanted the content to be easily understood and maintained a fifth-grade reading level throughout the source. ${ }^{[40]}$ In a separate study Piredda and colleagues ${ }^{[49]}$ developed an information booklet about implanted ports for chemotherapy access. The content was written using plain language, attractive design, colors, and graphics. Forty people evaluated the booklet for clarity and readability. The investigators improved the graphics and text based on the feedback. ${ }^{[49]}$ Lastly, Rigdon ${ }^{[39]}$ developed brochures following a review of the literature for teaching patients with low literacy including simple language, large font, and active voice. Participants gave positive feedback on the teaching materials and all but one of the participants found the material to be beneficial. Only one of the participants said she did not recall one of the education sessions but correctly answered every question on the follow-up survey. ${ }^{[39]}$

The use of graphics also appeared in three studies. ${ }^{[39,48,51]}$ Jazieh and Brown ${ }^{[51]}$ used large graphics to alert participants to important information. For example, the stop sign was placed in a chemotherapy teaching booklet to alert the participants to stop and seek help if they experienced sudden complications. ${ }^{[51]}$ Rigdon $^{[39]}$ also used illustrations and images within the educational brochure to highlight chemotherapy side effects. Graphics included an image of a thermometer to remind patients to take their temperature daily. Another image included a man brushing his teeth as a cue for participants to report mouth sores to the clinic nurse to prevent mucositis ${ }^{[39]}$ Lastly, Fee-Schroeder and others ${ }^{[48]}$ designed a DVD with audiovisuals which implemented health literacy principles recommended by expert reviewers. However, the authors did not specifically describe which health literacy principles were used within the DVD. ${ }^{[48]}$

\subsubsection{Pilot testing materials}

Authors of three articles tested materials prior to using with patients. ${ }^{[20,49,50]}$ Gonzalez and Stepan ${ }^{[50]}$ received feedback from patients, families, and nurses prior to formatting an educational booklet. The authors held sessions to encourage feedback while developing the booklet. ${ }^{[50]}$ Additionally, Piredda and others ${ }^{[49]}$ used similar testing in developing their information booklet. Forty people with a variety of educational backgrounds reviewed the booklet where the authors made revisions prior to distributing to the participants. ${ }^{[49]}$ In contrast, Foltz and Sullivan ${ }^{[20]}$ tested materials already available to the public. In a series of focus groups participants discussed and explored the layout, content, and wording of

Published by Sciedu Press two educational brochures from the National Cancer Institute (NCI) and the American Cancer Society (ACS). ${ }^{[20]}$ Participants unanimously preferred the ACS brochure for providing more information than the NCI pamphlet. Several of the participants commented that more information should be included about sexuality. ${ }^{[20]}$ The pilot testing of materials of these three studies provided an opportunity for materials to be edited to meet a variety of patients' learning needs.

\section{Discussion}

This review demonstrated that few studies use theory to specifically guide the development of chemotherapy education materials. In fact, more than half of the included studies did not use a theory to guide their work. Studies grounded in theory have a framework for creating and implementing effective chemotherapy educational programs. ${ }^{[52]}$ Theory can provide an outline to provide insights into interventions and nursing practice. ${ }^{[52]}$ Additionally, using an appropriate theory may help guide researchers when incorporating health literacy principles within their chemotherapy education materials.

Furthermore, the inclusion of health literacy principles was used sparsely in the chemotherapy education materials for patients with breast cancer. Eleven articles were excluded during the full-text review for lacking a description of a health literacy principles used within the educational materials. Including a description of the health literacy principles could be beneficial for researchers developing chemotherapy education materials. An explicit description using health literacy principles could serve as a guide for creating educational material for not only breast cancer, but also other cancers.

Testing the knowledge gained from the education is critical to measuring the effectiveness of the chemotherapy material. ${ }^{[53]}$ However, most of the studies in our review were limited to post-test only and outcome evaluation of the education. Only one article included pre- and post-testing with an outcome of knowledge. ${ }^{[49]}$ While educational chemotherapy materials implement health literacy principles, knowledge is rarely examined as an outcome. The limited type of post-test only research designs is not conclusive in establishing a relationship between health literacy principles and chemotherapy knowledge. Furthermore, only in one study did the authors measured participants' health literacy as part of an assessment to measure learning preferences and styles. ${ }^{[27]}$ Educational materials may implement health literacy principles, but the effectiveness of such materials should be measured with consideration of the patient's baseline health literacy. This will allow the researchers to determine the effect, if any, of the health literacy principles used in the materials. The 
educational benefit of these materials has not been consistently demonstrated in chemotherapy education unlike the educational information available for diabetes and heart failure. Investigators found a significant increase in the patients' knowledge after they viewed a multimedia diabetes educational program designed for patients with low literacy. ${ }^{[54]}$ Similarly, self-care knowledge of heart failure management increased after patients viewed low literacy educational materials. ${ }^{[55]}$

The evaluation studies offer valuable feedback from patients and demonstrate overall acceptability of the materials. Patients rated print size and readability as very satisfactory in a patient information packet. ${ }^{[51]}$ These preferences illuminate the benefit of specific health literacy principles (active voice, use of bulleted lists, friendly tone) in delivering chemotherapy information.

Even if educational materials are developed using health literacy principles, the impact of the educator, including cancer nurse educators, has not been thoroughly explicated in the breast cancer literature. Much of the literature that includes health literacy principles in educational materials pertains to chronic diseases such as diabetes and asthma ${ }^{[56,57]}$ but not to breast cancer patients thereby warranting further exploration for breast cancer. Most patients receive written chemotherapy information and nurse educators may teach to supplement the materials. Effective teaching can lead to increased patient involvement and retention, whereas ineffective teaching can result in reduced comprehension. ${ }^{[53,58]}$ Oncology nurses may evaluate current chemotherapy materials and adjust teaching if materials lack health literacy principles. If nurses are concerned that health literacy principles are not being included in the materials, nurses can use techniques to supplement to the materials such as highlighting and underlining important sections within the materials. Nurses may use white space to make bulleted lists to emphasize teaching points. ${ }^{[43,44]}$ Nurses may also use the teach-back method with patients to correspond with the education materials. The teach-back method could be a supplemental tool to aid in comprehension and retention. ${ }^{[59]}$ By including health literacy principles during chemotherapy teaching, the nurse is better able to assist in patient learning and retention of chemotherapy information, which could ultimately improve overall health outcomes and extend quality of survivorship. ${ }^{[17]}$

\subsection{Limitations}

Our review has limitations. We did not use an international database such as Embase (Excerpta Medica database) which may have prevented us from identifying relevant articles from other countries and in other languages. Secondly, the $\mathrm{MeSH}$ terms and keywords may have been limiting; other combinations may have yielded different results.

\subsection{Future research}

We identified gaps from the limited amount of published literature regarding the incorporation of health literacy principles within chemotherapy education for patients with breast cancer. Much of the chemotherapy education material development lacked the application of health literacy principles and researchers did not test the effectiveness of the materials on knowledge.

Incorporating health literacy principles into chemotherapy education materials for women with breast cancer is imperative. Using health literacy principles should improve overall comprehension of chemotherapy education thereby increasing adherence, assisting with symptom management, and improving quality of life while going through treatment. Furthermore, implementing health literacy principles within immunotherapy and oral chemotherapy materials is vital as patients are increasingly being prescribed these therapies. ${ }^{[10,60,61]}$

Specifically, in oral chemotherapy, the application of health literacy principles within educational materials could potentially be even more critical because the patient is responsible for the administration. ${ }^{[62,63]}$ Effective instruction prior to beginning oral chemotherapy is vital to combat against barriers to adherence such as poor health literacy, complexity of dosing, and drug side effects. ${ }^{[62]}$ Future research may be directed towards measuring the impact of health literacy principles in chemotherapy education on improving adherence. Researchers may consider testing the effect of education in patients' managing their side effects or promoting better communication with physicians.

Furthermore, researchers did not measure the effectiveness of chemotherapy materials on increasing knowledge. Researchers may consider developing and testing materials prior to disseminating chemotherapy materials to patients to encourage adherence to oral and intravenous chemotherapy. The revision and testing process may continue throughout the material development. Investigators can conduct studies to measure knowledge gained after exposure to materials using reliable and valid instruments. However, patient health literacy may need to be examined at baseline to determine any relationship with knowledge. ${ }^{[54]}$

\section{Conclusion}

This review provides evidence of the need for further exploration and implementation of health literacy principles within chemotherapy education for women with breast cancer. Incorporating health literacy principles within chemotherapy 
education could assist in women's comprehension and retention of chemotherapy education ultimately improving overall health outcomes and extending survivorship.

\section{ACKNOWLEDGements}

This research was supported by a grant from Susan G.

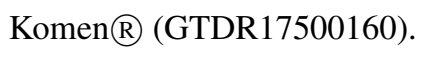

\section{CONFLICTS OF INTEREST Disclosure}

The authors declare that there is no conflict of interest.

\section{REFERENCES}

[1] American Cancer Society. Cancer facts and figures 2016. Atlanta, GA: American Cancer Society. 2016.

[2] American Cancer Society. What are the key statistics about breast cancer in men? 2017. Available from: https://www. cancer.org/cancer/breast-cancer-i n-men/about/key-statistics.html

[3] American Cancer Society. Breast cancer facts and figures 2015-2016. Atlanta, GA. 2015.

[4] National Cancer Institute. Breast cancer treatment. 2015. Available from: http://www. cancer.gov/types/breast/patient/ breast-treatment-pdq-section/_125

[5] Iacorossi L, Gambalunga F, Fabi A, et al. Adherence to oral administration of endocrine treatment in patients with breast cancer: A qualitative study. Cancer Nursing. 2016 Dec 05. PMid:27922917 https://doi.org/10.1097/NCC. 0000000000000452

[6] Hershman D, McBride R, Jacobson JS, et al. Racial disparities in treatment and survival among women with early-stage breast cancer. Journal of Clinical Oncology. 2005 Sep 20; 23(27): 6639-46. PMid:16170171 https://doi.org/10.1200/JC0.2005.12.63 3

[7] Greer JA, Amoyal N, Nisotel L, et al. A systematic review of adherence to oral antineoplastic therapies. The Oncologist. 2016 Mar; 21(3): 354-76. PMid:26921292 https://doi.org/10.1634/th eoncologist. 2015-0405

[8] Williams SA, Schreier AM. The effect of education in managing side effects in women receiving chemotherapy for treatment of breast cancer. Oncology Nursing Forum. 2004 Jan-Feb; 31(1): E16-23. PMid:14722602 https://doi.org/10.1188/04.0NF.E16-E23

[9] Kidwell KM, Harte SE, Hayes DF, et al. Patient-reported symptoms and discontinuation of adjuvant aromatase inhibitor therapy. Cancer. 2014 Aug 15; 120(16): 2403-11. PMid:24802413 https: //doi.org/10.1002/cncr. 28756

[10] Thompson N, Christian A. Oral chemotherapy: Not just an ordinary pill. American Nurse Today. 2016; 11(9): 16-21.

[11] Muluneh B, Deal A, Alexander MD, et al. Patient perspectives on the barriers associated with medication adherence to oral chemotherapy. Journal of Oncology Pharmacy Practice. 2016 Nov 28. PMid:27895220 https://doi.org/10.1177/10781552166790 26

[12] Partridge AH, Archer L, Kornblith AB, et al. Adherence and persistence with oral adjuvant chemotherapy in older women with earlystage breast cancer in CALGB 49907: adherence companion study 60104. Journal of Clinical Oncology. 2010 May 10; 28(14): 2418-22. PMid:20368559 https://doi.org/10.1200/JC0.2009.26.46 71

[13] Rieger PT, Yarbro CH. Role of the oncology nurse. In: Kufe DW, Pollock RE, Weichselbaum RR, Bast RC, Gansler TS, Holland JF, et al., editors. Holland-Frei Cancer Medicine. 6th ed. Shelton, CT: People's Medical Publishing House; 2003.

[14] Traeger L, McDonnell TM, McCarty CE, et al. Nursing intervention to enhance outpatient chemotherapy symptom management: Patient- reported outcomes of a randomized controlled trial. Cancer. 2015 Nov 1; 121(21): 3905-13. PMid:26194461 https://doi.org/10 $.1002 /$ cncr. 29585

[15] Henderson K, Gosbee A, Classen L, et al. Breast cancer chemotherapy education: Taking it from the classroom to the computer. Oncology Nursing Forum. 2015 Mar; 42(2): E113-E.

[16] Morgan ER, Laing K, McCarthy J, et al. Using tablet-based technology in patient education about systemic therapy options for earlystage breast cancer: A pilot study. Current Oncology. 2015 Oct; 22(5): E364-E9. PMid:26628877 https://doi .org/10.3747/co .22 .2476

[17] Valenti RB. Chemotherapy education for patients with cancer: A literature review. Clinical Journal of Oncology Nursing. 2014; 18(6): 637-40. PMid:25427698 https://doi.org/10.1188/14.CJON . 637-640

[18] Dalby CK, Nesbitt M, Frechette CA, et al. Standardization of initial chemotherapy teaching to improve care. Clinical Journal of Oncology Nursing. 2013; 17(5): 472-5. PMid:24080045 https: //doi.org/10.1188/13.CJON.472-475

[19] Felder RM, Silverman LK. Learning and teaching styles in engineering education. Engineering Education. 1988; 78(7): 674-81.

[20] Foltz AT, Sullivan JM. Limited literacy revisited: Implications for patient education. Cancer Practice. 1999; 7(3): 145-50. https: //doi.org/10.1046/j.1523-5394.1999.07304.x

[21] Institute of Medicine. Health literacy: A prescription to end confusion. Washington, DC: 2004.

[22] Davis TC, Williams MV, Marin E, et al. Health literacy and cancer communication. CA: A Cancer Journal for Clinicans. 2002 May-Jun; 52(3): 134-49.

[23] Davis TC, Dolan NC, Ferreira MR, et al. The role of inadequate health literacy skills in colorectal cancer screening. Cancer Investigation. 2001; 19(2): 193-200. PMid:11296623 https ://doi .org/ 10.1081/CNV-100000154

[24] Busch EL, Martin C, DeWalt DA, et al. Functional health literacy, chemotherapy decisions, and outcomes among a colorectal cancer cohort. Cancer control: Journal of the Moffitt Cancer Center. 2015 Jan; 22(1): 95-101.

[25] Huynh TK, Trovato JA. Assessment of patients' knowledge and management of chemotherapy-realted adverse effects. Journal of Hematology Oncology Pharmacy. 2014; 4(4).

[26] Krzyzanowska MK, Treacy J, Maloney B, et al. Development of a patient registry to evaluate hospital admissions related to chemotherapy toxicity in a community cancer center. Journal of Oncology Practice. 2005 May; 1(1): 15-9. PMid:20871674 https://doi.org/10.1 200/jop. 2005.1.1.15

[27] Mann KS. Education and health promotion for new patients with cancer: A quality improvement model. Clinical Journal of Oncology Nursing. 2011; 15(1): 55-61. PMid:21278041 https://doi.org/ 10.1188/11. CJON.55-61

[28] Petty JL. Medication adherence and patient outcomes: Part 2: Interventions and resources to overcome low health literacy. Clinical Nurse Specialist: The Journal for Advanced Nursing Practice. 2013 
Nov-Dec; 27(6): 286-8. https://doi.org/10.1097/NUR.0b01 3e3182a872f 9

[29] Osborne H. Health literacy from A to Z: Practical ways to communicate your health message. 2nd ed. Burlington, MA: Jones \& Bartlett Learning; 2013.

[30] Garcia SF, Hahn EA, Jacobs EA. Addressing low literacy and health literacy in clinical oncology practice. Journal of Supportive Oncology. 2010 Mar-Apr; 8(2): 64-9.

[31] The Plain Language Action and Information Network (PLAIN). Improving communication from the federal government to the public. Available from: http://plainlanguage.gov/

[32] Stableford S, Mettger W. Plain language: A strategic response to the health literacy challenge. Journal of Public Health Policy. 2007; 28(1): 71-93. PMid:17363939 https://doi.org/10.1057/palg rave.jphp. 3200102

[33] Centers for Disease Control and Prevention. Simply put: A guide for creating easy-to-understand materials. 3rd ed. 2009.

[34] Doak CC, Doak LG, Friedell GH, et al. Improving comprehension for cancer patients with low literacy skills: Strategies for clinicians. CA: A Cancer Journal for Clinicians. 1998; 48(3): 151-62. https://doi.org/10.3322/canjclin.48.3.151

[35] Centers for Disease Control and Prevention. Visual communication. 2014; Available from: http://www.cdc.gov/healthliteracy /developmaterials/visual-communication.html

[36] Doak CC, Doak LG, Root JH. Teaching patients with low health literacy. Philadelphia, PA: Lippincott; 1996.

[37] Grant MJ, Booth A. A typology of reviews: An analysis of 14 review types and associated methodologies. Health Information and Libraries Journal. 2009 Jun; 26(2): 91-108. PMid:19490148 https://doi.org/10.1111/j.1471-1842.2009.00848.x

[38] Arksey H, O'Malley L. Scoping studies: Towards a methodological framework. International Journal of Social Research Methodology. 2005; 8(1): 19-32. https://doi.org/10.1080/136455703200 0119616

[39] Rigdon AS. Development of patient education for older adults receiving chemotherapy. Clinical Journal of Oncology Nursing. 2010; 14(4): 433-41. PMid:20682499 https://doi.org/10.1188/10 .CJON . 433-441

[40] Sullivan CM, Dalby C, Gross AH, et al. Oral chemotherapy education: Using innovation to ensure broad access. Clinical Journal of Oncology Nursing. 2016 Apr; 20(2): 126-8. PMid:26991703 https://doi.org/10.1188/16. CJON.126-128

[41] Orem DE. Orem's general theory of nursing. In: Prase R, editor. Nursing science: Major paradigms, theories, and critiques. Philadelphia, PA: W.B. Saunders; 1987. PMid:3441310

[42] Best JT. Effective teaching for the elderly: Back to basics. Orthopedic Nursing. 2001 May-Jun; 20(3): 46-52. PMid:12025634 https://doi.org/10.1097/00006416-200105000-00008

[43] Murphy PW, Davis TC. When low literacy blocks compliance: Here's how you can identify patients with a reading problem and tailor your teaching accordingly. RN. 1997; 60(10): 58-63. PMid:9369773

[44] Duffy MM, Snyder K. Can ED patients read your patient education materials? Journal of Emergency Nursing. 1999; 25(4): 294-7. https://doi .org/10.1016/S0099-1767 (99) 70056-5

[45] King IM. King's theory of goal attainment. Nursing Science Quarterly. 1992; 5: 19-26. PMid:1538850 https://doi.org/10.117 $7 / 089431849200500107$

[46] King IM. A theory for nursing: Systems, concepts, and process. New York, NY: John Wiley and Sons; 1981.
[47] Doran DM, Sidani S. Outcomes-focused knowledge translation: A framework for knowledge translation and patient outcomes improvement. Worldviews on Evidence-Based Nursing. 2007 1st Quarter; 4(1): 3-13.

[48] Fee-Schroeder K, Howell L, Kokal J, et al. Empowering individuals to self-manage chemotherapy side effects. Clinical Journal of Oncology Nursing. 2013 Aug; 17(4): 369-71. PMid:23899974 https://doi.org/10.1188/13.CJON.369-371

[49] Piredda M, Migliozzi A, Biagioli V, et al. Written information improves patient knowledge about implanted ports. Clinical Journal of Oncology Nursing. 2016 Apr; 20(2): E28-E33. PMid:26991720 https://doi.org/10.1188/16.CJON.E28-E33

[50] Gonzalez A, Stepan KA. Brief Report: A systematic process to design a useful chemotherapy education packet for patients at U.T.M.D. Anderson Cancer Center. Journal of Cancer Education. 2006; 21(1): 40-2.

[51] Jazieh AR, Brown D. Development of a patient information packet for veterans with cancer receiving chemotherapy. Journal of Cancer Education. 1999 Summer; 14(2): 96-8.

[52] Meleis AI. Theoretical Nursing: Development \& Progress. 5th ed. Philadelphia, PA: Lippincott Williams \& Wilkins; 2012.

[53] Harris A. Effective teaching: A review of the literature. School Leadership \& Management. 1998; 18(2): 169-83.

[54] Kandula NR, Nsiah-Kumi PA, Makoul G, et al. The relationship between health literacy and knowledge improvement after a multimedia type 2 diabetes education program. Patient Education and Counseling. 2009; 75(3): 321-7.

[55] Dickson VV, Chyun D, Caridi C, et al. Low literacy self-care management patient education for a multi-lingual heart failure population: Results of a pilot study. Applied Nursing Research. 2016 Feb; 29: 122-4. PMid:26856501 https://doi.org/10.1016/j . apnr .2015 .06 .002

[56] Kim SH, Lee A. Health-literacy-sensitive diabetes self-management interventions: A systematic review and meta-analysis. Worldviews on Evidence-Based Nursing. 2016 Apr 22. https ://doi.org/10 $.1111 /$ wvn. 12157

[57] Yin HS, Gupta RS, Tomopoulos S, et al. Readability, suitability, and characteristics of asthma action plans: Examination of factors that may impair understanding. Pediatrics. 2013 Jan; 131(1): e116-26. PMid:23209106 https://doi.org/10.1542/peds . 2012-0612

[58] Friedman AJ, Cosby R, Boyko S, et al. Effective teaching strategies and methods of delivery for patient education: A systematic review and practice guideline recommendations. Journal of Cancer Education. 2011 Mar; 26(1): 12-21. PMid:21161465 https: //doi.org/10.1007/s13187-010-0183-x

[59] Caplin M, Saunders T. Utilizing teach-back to reinforce patient education: A step-by-step approach. Orthopedic Nursing. 2015 Nov-Dec; 34(6): 365-8. PMid:26575509 https://doi .org/10.1097/NOR . 0000000000000197

[60] Weingart SN, Bach PB, Johnson SA, et al. NCCN Task Force Report: Oral chemotherapy. Journal of the National Comprehensive Cancer Network. 2008; 6(3): S1-S14. PMid:18377852

[61] Hassett M. How can nurses help patients adhere to their oral chemotherapy? 2016.

[62] Given BA, Spoelstra SL, Grant M. The challenges of oral agents as antineoplastic treatments. Seminars in Oncology Nursing. 2011 May; 27(2): 93-103. PMid:21514479 https://doi .org/10.101 $6 / j$. soncn. 2011.02.003

[63] Barton D. Oral agents in cancer treatment: The context for adherence. Seminars in Oncology Nursing. 2011 May; 27(2): 104-15. PMid:21514480 https://doi.org/10.1016/j.soncn.2011.0 2.002 